\title{
Insulinoma Treated As Epilepsy; a Case of Misdiagnosis
}

\begin{abstract}
Keywords: Insulinoma; Epilepsy; Seizure; Learning disability Abstract

Insulinoma is a rare neuroendocrine tumour. It can occur at any age with nonspecific signs and symptoms. Due to its nonspecific clinical features, insulinoma may be misdiagnosed with other disorders. While evaluating a patient presenting with a seizure, toxic and metabolic causes should always be considered as they are potentially curable and can be fatal if left untreated. We describe a case of hypoglycaemia induced seizures treated as epilepsy in a patient with learning disability.
\end{abstract}

\section{Case History}

A49 year old female with learning disability and 2 years history of epilepsy was admitted following a siezure like activity and fall during a routine visit to her GP surgery. She had sustained injury to left knee and $\mathrm{x}$ - ray confirmed a distal femur and a patellar fracture. On admission her serum glucose was $2.0 \mathrm{mmol}$, all other routine blood tests including Full Blood Count, Renal function and Liver function test were normal. Her regular medications included Lamotrigine and Mebeverien. On the ward she had recurrent spontaneous hypoglycaemic episodes requiring regular treatment with glucose infusions. The lowest capillary blood glucose recorded was 1.9 mmol. Due to the learning disability, patient could not describe any symptoms usually experienced at the onset of hypoglycaemia. Glycated Haemoglobin (HbA1c) was $19.0 \mathrm{mmol}$ (Ref range: 20$41 \mathrm{mmol}$ ) indicating lower than normal average glucose. Random cortisol and thyroid function test were normal. She underwent left knee exploration and repair of medial retinaculum of quadriceps tendon and excision of patellar fragment. While awaiting results of further investigations, Diazoxide was initiated with good effect. The results of the specific biochemical investigations for her recurrent hypoglycaemia were consistent with endogenous hyperinsulinaemic hypoglycaemia (Table 1).

A CT scan abdomen and pelvis was normal. Endoscopic ultrasound was performed that showed a small $13 \times 9 \mathrm{~mm}$ well defined lesion with good doppler signals indicating high vascularity raising the possibility of a Neuroendocrine tumour (Image 1). Biopsies taken from the pancreatic lesion (Image 2) showed clusters of ovoid epithelial cells with bland nuclei resembling those of neuroendocrine cells that stained with synaptophysin and chromogranin in addition to BerEP4 consistent with a well-differentiated neuroendocrine tumour.

Patient was referred and discussed with the regional Neuroendocrine centre. The pancreatic lesion was surgically excised with enucleation of the mass resulting in complete resolution of the symptoms.

\section{Discussion}

Spontaneous hypoglycaemia can be difficult to diagnose in

\section{Advances in}

Diabetes \& Endocrinology

\author{
Mian $\mathbf{F J}^{\mathbf{J}^{\star}}$, Yousuf $\mathbf{Q}^{2}$ and Khan $\mathbf{A A}^{3}$ \\ ${ }^{I}$ Consultant Physician in Endocrinology and Diabetes, UK \\ ${ }^{2}$ Specialist Registrar Endocrinology and Diabetes UK \\ ${ }^{3}$ Consultant Physician in Endocrinology and Diabetes, UK \\ *Address for Correspondence \\ Mian FJ, Consultant Physician in Endocrinology and Diabetes, Manor Hospital, \\ Walsall Healthcare NHS Trsut Walsall, West Midlands, WS2 9PS, UK \\ Submission: 04-March, 2020 \\ Accepted: $10-$ April, 2020 \\ Published: 13-April, 2020 \\ Copyright: () 2020 Mian FJ, et al. This is an open access article \\ distributed under the Creative Commons Attribution License, which \\ permits unrestricted use, distribution, and reproduction in any medium, \\ provided the original work is properly cited.
}

patients with a learning disability as patient may be unable to describe hypoglycaemia related symptoms. Hypoglycaemia can exhibit various neurogenic and neuroglycopenic symptoms. These can mimic neuropsychiatric symptoms including unconsciousness, confusion, seizure, personality change and bizarre behaviour in most patients [1,2]. Over half of patients with these symptoms are initially misdiagnosed with neuropsychiatric disorders such as epilepsy $[1,3]$. The siezures can be tonic-clonic, complex partial or absence seizures [4-6]. However, correct diagnosis of epilepsy is also challenging in clinical settings and can lead to inappropriate treatment with antiepileptic medication. In the setting of an Insulinoma, these symptoms become typically evident after fasting and are often precipitated by physical exercises. However, the median duration of symptoms before diagnosis remains variable and can reach 12-18 months on average or even years in rare cases [7].

An insulinoma is a rare pancreatic endocrine tumour that is typically sporadic, solitary, and usually less than $2 \mathrm{~cm}$ in diameter. It is reported in 1-4 people per one million person years1. Because of the nonspecific symptoms, insulinoma may be misdiagnosed with other disorders. It can be seen at any age and occurs slightly more frequently in women than in men [8,9]. The clinical clues suggesting insulinoma are based on the clinician's recognition of the presence of hypoglycaemic symptoms included in Whipple's triad [10,11]. This triad includes symptoms of hypoglycaemia induced by fasting or exercise, plasma glucose less than $2.5 \mathrm{mmol}$ and relief of symptoms following the administration of glucose. A previous diagnosis of

Table 1: Biochemical investigation indicating endogenous hyperinsulinaemic hypoglycaemia.

\begin{tabular}{|c|c|}
\hline Investigation & Results \\
\hline Serum Glucose & 2.2 \\
\hline Insulin & $20000 \mathrm{pmol} / \mathrm{l}$ \\
\hline C- Peptide & $1160 \mathrm{pmol} / \mathrm{l}$ \\
\hline Insulin Antibodies & Negative \\
\hline Sulfonyl urea Screen & Negative \\
\hline
\end{tabular}




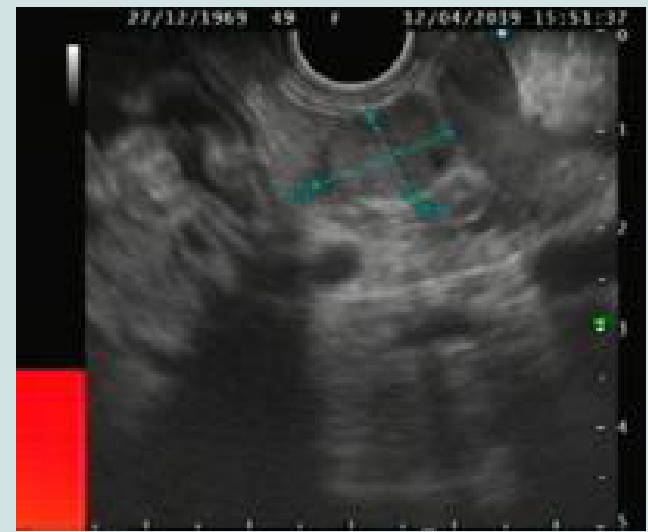

Image 1: EUS showing a well-defined hypoechoic lesion on the tail of Pancreas.

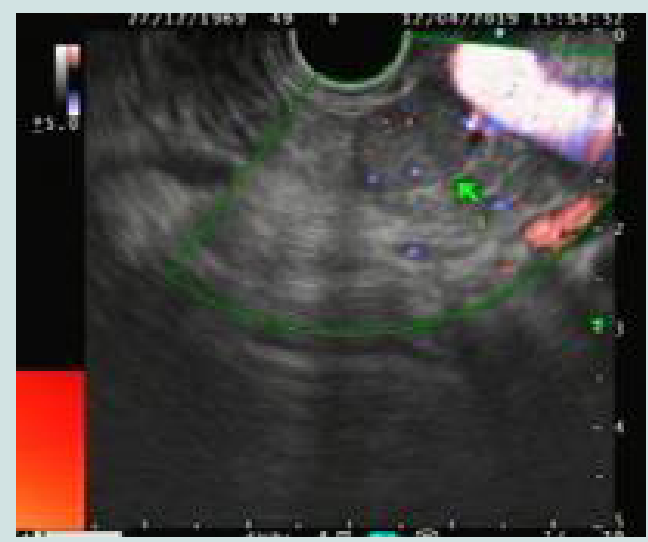

Image 2: EUS with FNA of the pancreatic lesion.

epilepsy and/or a drug history of anti-epileptic drugs can obscure the clinical relationship between patient symptoms and possible hypoglycaemia.

Most insulinomas are benign and are associated with MEN 1 in $5 \%$ of patients. It is estimated that $21 \%$ of patients with MEN1 develop insulinomas $[12,13]$. The incidence is $3-10$ cases per million people per year. The insulinomas occurring in this autosomal dominant syndrome have a higher risk of relapse [14].

The supervised $72 \mathrm{~h}$ fasting test remains the gold standard for biochemical diagnosis with measurement of plasma glucose, insulin, C-peptide, and proinsulin during the onset of hypoglycaemic symptoms. Various preoperative procedures can be used to localize the tumour in order to plan therapeutic strategy. The reported sensitivity of conventional CT and MRI for detection of pancreatic insulinoma ranges respectively from 33-64\% and 40-90\% respectively. However, the advent of helical CT scan has enabled detection of approximately $94 \%$ of insulinomas $[15,16]$.

Endoscopic Ultrasound (EUS) is now largely considered as the best investigation for preoperative localization of insulinoma with a sensitivity of up to $94 \%$. It can detect even small tumours of up to 5 $\mathrm{mm}$, and reveal important relation to the bile duct and adjacent blood vessels. In addition EUS allows performing fine-needle aspiration cytology of suspicious lesions and preoperative marking of tumours to facilitate surgical excision particularly with laparoscopic approach. However, EUS findings largely depend on clinical experience $[8,15]$.

Medical management of insulinoma, used to treat and prevent hypoglycaemia, is generally restricted to un-resectable metastatic tumours, unsuccessful operation with persistent symptoms, inoperable patients, and patients waiting or refusing surgery $[3,15]$. Moreover, other recent techniques for the management of insulinoma have been reported I Including injection of octreotide; EUS guided alcohol ablation, radiofrequency ablation [17], or embolization of an insulinoma.

Surgical excicion is the treatment of choice for most Insulinomas. Tumour enucleation is the procedure of choice especially in case of small and solitary nodule that is not encroaching on the pancreatic or bile ducts [18]. More recently robotic enucleation of intrapancreatic Insulinoma has also been reported [11]. Pancreatic resection is indicated for lesions invading or in close proximity to the pancreatic duct or major vessels or suspicious for malignancy [19]. Resection options include distal pancreatectomy (with or without splenectomy), Whipple procedure (pancreaticoduodenectomy), or median pancreatectomy, depending on the site of insulinoma.

Insulinomas are typically reddish-brown, firm, and encapsulated with a clear plane of dissection between the tumour and surrounding soft pancreatic parenchyma [20].

Histologically, insulinomas are epithelial neoplasms associated with strong and diffuse immunohistochemically expression of neuroendocrine markers such as synaptophysin and chromogranin. Mitotic rate (number of mitoses per $10 \mathrm{HPF}$ ) and proliferation index (Ki-67 labelling index) are particularly helpful to separate welldifferentiated from poorly differentiated tumours $[21,22]$.

\section{Conclusion}

Careful assessment is required to exclude hypoglycaemia as the cause of siezures in all patients in general and particularly in patients with learning disability as it is easily treatable and the underlying cause such as Insulinoma potentially curable.

\section{Recommendation}

We recommend exclusion of hypoglycaemia as a causein all patients presenting with siezures.

\section{References}

1. Imamura M, Nakamoto Y, Uose S, Komoto I, Awane M, et al. (2015) Diagnosis of functioning pancreaticoduodenal neuroendocrine tumors. J Hepatobiliary Pancreat Sci 22: 602-609.

2. Bouslama K, Maghrebi H, Bedioui H, Bouslama K (2014) Pancreatic insulinoma: diagnostic approach and therapeutic modalities. J Afr Hépatol Gastroentérol 8: 11-15.

3. Whipple AO, Frantz VK (1935) Adenoma of islet cells with hypeinsulinism: a review. Ann Surg 101: 1299-1335.

4. Qi Z, Li D, Ma J, Xu P, Hao Y, et al. (2020) Insulinoma presenting as a complex partial seizure: still a possible misleading factor. Front Neurosci 13: 1388.

5. Gowda SN, Abdullah HM, Sethi P, Cunningham A, Askeland R, et al. (2019) When absence seizures are not seizure: a case of insulinoma. S D Med 72: 552-555. 
6. Kaçmaz E, Zwart MJW, Engelsman AF, Busch OR, Nieveen van Dijkum EJM, et al. (2020) Robotic enucleation of an intra-pancreatic insulinoma in the pancreatic head. J Vis Exp 155.

7. Ali ZA (2013) Insulinoma. MedScape.

8. Patel S, Narwari M, Parekh D, Shah V (2013) Insulinoma: case report and review of Diagnostic and treatment modalities. J Assoc Physicians India 61: 423-426

9. Ding Y, Wang S, Liu J, Yang Y, Liu Z, et al. (2010) Neuropsychiatric profiles of patients with insulinomas. Eur Neurol 63: 48-51.

10. Imamura M (2010) Recent standardization of treatment strategy for pancreatic Neuroendocrine tumors. World J Gastroenterol 16: 4519-4525.

11. Graves TD, Gandhi S, Smith SJ, Sisodiya SM, Conway GS (2004) Misdiagnosis of seizures: insulinoma presenting as adult-onset seizure disorder. J Neurol Neurosurg Psychiatry 75: 1091-1092.

12. Service FJ, McMahon MM, O'Brien PC, Ballard DJ (1991) Functioning insulinoma: incidence, recurrence, and long-term survival of patients: a 60 year study. Mayo Clin Proc 66: 711-719.

13. Boukhman MP, Karam JH, Shaver J, Siperstein AE, Duh QY, et al. (1998) Insulinoma - experience from 1950 to 1995. West J Med 169: 98-104.
14. Abboud B, Boujaoude J (2008) Occult sporadic insulinoma: localization and surgical strategy. World J Gastroenterol 14: 657-665.

15. Okabayashi T, Shima Y, Sumiyoshi T, Kozuki A, Ito S, et al. (2013) Diagnosis and Management of insulinoma. World J Gastroenterol 19: 829-837.

16. Finlayson E, Clark OH (2004) Surgical treatment of insulinomas. Surg Clin North Am 4: 775-785.

17. Kluz M, Staroń R, et al. (2019) Successful endoscopic ultrasound-guided radiofrequency ablation of a pancreatic insulinoma. Pol Arch Intern Med 130 145-146.

18. Grant CS (2005) Insulinoma. Best Pract Res Clin Gastroenterol 19: 783-798.

19. Vanderveen K, Grant C (2010) Insulinoma. Cancer Treat Res 153: 235-252.

20. Klimstra DS, Modlin IR, Coppola D, Lloyd RV, Suster S (2010) The pathologic classification of neuroendocrine tumors: a review of nomenclature, grading, and staging systems. Pancreas 39: 707-712.

21. Murakami T, Yamashita T, Yabe D, Masui T, Teramoto Y, et al. (2017) Insulinoma with a History of Epilepsy: Still a Possible Misleading Factor in the Early Diagnosis of Insulinoma. Intern Med 56: 3199-3204.

22. Dizon AM, Kowalyk S, Hoogwerf BJ (1999) Neuroglycopenic and other symptoms in patients with insulinomas. Am J Med 106: 307-310. 